\title{
Resgatando arquivos: história custodial do fundo secretaria de Governo da Capitania de São Paulo
}

Recovering Archives: The Custodial History of the Captaincy of São Paulo's Archival Holdings

Marcelo Thadeu Quintanilha Martins*

\section{RESUMO}

Este artigo condensa um trabalho minucioso de tratamento documental visando a descrição do arquivo da Secretaria de Governo da capitania de São Paulo, custodiado pelo Arquivo Público do Estado de São Paulo. Tendo por objetivo compreender a lógica de acumulação e produção de documentos do fundo mediante trabalho interdisciplinar que dialoga com a História e a Arquivologia, o tratamento aqui apresentado busca resgatar do interior dos arquivos a sua própria história. Respeitando os princípios arquivísticos segundo os quais a organização de um fundo deve representar a lógica de funcionamento da sua entidade produtora, contribuindo assim para o entendimento das funções e atividades geradoras dos documentos, $\mathrm{o}$ artigo lança luz também para os acidentados caminhos percorridos pelos arquivos da administração luso-brasileira até servirem de fonte para os historiadores.

Palavras-chave: Capitania de São Paulo; arquivo; história dos arquivos.

\section{Abstract}

This article summarizes the detailed work involved in an archival processing project to describe the historical manuscripts of the Government Secretariat of the Captaincy of São Paulo, held today by the São Paulo State Public Archive. Seeking to understand the logic of accumulation and production of the holdings through an interdisciplinary approach that combines history and archival science, the project sought to recover the history of the archives from their own sedimented layers. Respecting the archival principle that the organization of a fond should reflect the organic logic of its creator entity, thus contributing to the understanding of the functions and activities responsible for generating the documents, the article also sheds light on the complicated paths taken by the archives of the Luso-Brazilian administration until eventually becoming a source for historians.

Keywords: Captaincy of São Paulo; archive; archives history.

\footnotetext{
* Arquivo Público do Estado de São Paulo. São Paulo, SP, Brasil. m.tmartins@uol.com.br <https:// orcid.org/0000-0002-8620-8667>
} 
A história dos arquivos no Brasil ainda permanece encerrada no interior dos arquivos. Sabe-se que muitos documentos produzidos no período colonial se perderam ou estão dispersos por várias instituições. Outros, simplesmente, não estão descritos corretamente (Neves, 1997). Há relatos, por exemplo, de que a coleção de livros da Junta da Real Fazenda de Minas Gerais foi salva da destruição por puro acaso. Em 1929, um encarregado pelo governo do estado, procurando por documentos sobre os limites entre Minas e outras unidades da Federação, soube que funcionários do Arquivo e da Biblioteca Nacionais haviam arrecadado muitos papéis abandonados provenientes do governo da capitania, entregando o que restara para uma instituição de caridade como papel inútil. Essa instituição havia vendido os documentos para uma fábrica de papelão em Juiz de Fora. Informado, o governo de Minas recuperou 59 sacos de documentos, recolhidos ao Arquivo Público Mineiro (Boschi; Moreno; Figueiredo, 2006).

Nesse mesmo ano, em São Paulo, uma enchente do Tamanduateí destruiu os livros da Provedoria da Real Fazenda depositados no arquivo do Tesouro, perdendo-se uma parcela importante dos registros de sesmarias anteriores a 1721 (Rodrigues, 1965, p.171). Já o historiador Afonso de Taunay (1952, p.25) relata que quase todo arquivo santista produzido entre os séculos XVI e XVIII foi consumido por incêndios, pela voracidade dos insetos e pela incúria dos seus responsáveis. Além desses casos de perda total de acervos, Josemar Henrique de Melo (2013) aponta que, lamentavelmente, a maior parte dos arquivos produzidos pela administração luso-brasileira que sobreviveram às vicissitudes do tempo perdeu sua lógica e ordenação, dissipadas no convívio com acervos de natureza diversa.

Entre os primeiros arquivos instalados no Brasil estão os arquivos das capitanias, mais especificamente das capitanias reais, aquelas incorporadas ou compradas pela Coroa com o propósito de estabelecer um governo mais vigoroso nos seus domínios. A administração pombalina extinguiu definitivamente o sistema de capitanias hereditárias, concluindo um processo que se iniciara com a incorporação da capitania da Bahia, em 1548, e de Pernambuco, em 1654 (Saldanha, 1992). Em 1709 a Coroa portuguesa comprou as terras dos herdeiros de Martim Afonso de Souza e seu irmão, Pero Lopes de Souza, concedidas pelo rei aos dois donatários nos primeiros anos da colonização. Essas terras originaram uma nova unidade administrativa governada a partir de Vila Rica. ${ }^{1}$ Chamava-se, na época, capitania de São Paulo e das Minas de Ouro, e abrigava um território correspondente aos atuais estados de Minas Gerais, 
Goiás, Mato Grosso, Paraná, Rio Grande do Sul, São Paulo e Santa Catarina. Onze anos depois, em 1720, o rei desmembrou suas terras e constituiu a capitania de São Paulo separada das Minas de Ouro, nomeando um capitão-general para residir na cidade de São Paulo, elevada à condição de sede da capitania. ${ }^{2}$

O arquivo da Secretaria de Governo da capitania de São Paulo caracteriza-se por uma condição rara: a sorte de ter preservada parte da sua ordenação, como comprovaremos adiante. $\mathrm{O}$ fato de ele ter sido mantido sob o olhar dos presidentes de província, no antigo palácio de governo, permitiu a conservação de parte substancial da sua ordenação original, algo bastante incomum nesse tipo de acervo, pois a maioria dos documentos anteriores ao século XX, mesmo em Portugal, acabaram catalogados, reordenados e, em alguns casos, até mesmo encadernados de maneira incorreta. O arquivo da Secretaria de Governo da capitania é composto por documentos produzidos pelos 15 capitães-generais que governaram São Paulo e pela junta provisória de governo, entre 1721 e 1823. Ele contém documentos recebidos de conselhos e tribunais do Reino, produzidos por juízes, ouvidores e capitães-mores da capitania, além de autoridades de outras capitanias e por homens e mulheres de diversos estratos sociais pleiteando mercês e amparo para seus infortúnios. Destaca-se nele uma rica diversidade de espécies documentais, tais como instruções do Conselho Ultramarino, alvarás, avisos, bandos, cartas patentes, cartas régias, cartas de conta, leis, decretos, ofícios, editais, contratos de estanco, portarias, provisões, regimentos, petições, requerimentos, mapas de população, resoluções, autos e devassas.

À semelhança de outros arquivos do Antigo Regime, o arquivo da Secretaria de Governo da capitania era, além de instrumento de continuidade administrativa, ferramenta de poder. Cada capitania tinha suas atividades sistematicamente acompanhadas. A circulação de informação e guarda de documentos eram essenciais para o Império Atlântico Português. A exemplo da Europa, os arquivos das capitanias conservavam documentos que garantiam as bases sociais na América portuguesa, pois a expansão e a conquista de novos territórios dependiam de um complexo sistema de doações de mercês que reforçavam os laços de vassalagem (Olival, 2006; Raminelli, 2006). Todas as petições de mercês deveriam ser efetuadas por escrito e precisavam ser registradas em livros. Esse sistema permitia à Coroa distribuir ofícios, patentes e privilégios a indivíduos e grupos, estabelecendo assim pactos de lealdade com seus súditos. Tais concessões eram o desdobramento de uma cadeia que se estendia desde Portugal, criando um fator de coesão dentro do disperso Império português (Fragoso; Guedes; Krause, 2013, p.39-40). Nessa época o 
documento escrito havia se consolidado como ferramenta de governo, mediando as relações sociais e impondo práticas duradouras. Se por um lado os documentos se apresentavam como instrumentos de respeito e submissão, por outro estabeleceram um diálogo regrado com a sociedade, abrindo as portas da graça real mediante a aceitação de uma série de regras e protocolos (Gómez Gómez, 2003). Essas formalidades levaram os documentos a refletir, em sua gênese, forma e conteúdo, o mundo hierarquizado que os criou, proporcionando um espelho das práticas do Antigo Regime.

Embora seja um acervo de 31,06 metros lineares, os documentos da Secretaria de Governo da capitania representam apenas um pequeno segmento do acervo do Arquivo Público do Estado de São Paulo (Apesp). Formado por 15.837 metros lineares de documentos textuais e mais de 2 milhões de fotografias, mapas e plantas, 45 mil livros e mais de 8 mil títulos de jornais e revistas, provenientes de órgãos da administração pública estadual, entes privados e de instituições extintas, o Apesp tem um dos acervos mais ricos do Brasil. ${ }^{3}$ Criado em 1892 para recolher documentos dispersos por diversas repartições, abrigar os processos findos das novas secretarias e coligir estudos estatísticos para o governo paulista, o Apesp recebeu nos seus primeiros anos uma grande massa de papéis proveniente de secretarias e juizados extintos, de tabelionatos de notas instituídos no século XVIII e de algumas câmaras municipais do interior e litoral paulistas (Martins, 2013, p.235). Assim procedendo, as autoridades da época construíram um acervo valiosíssimo para os historiadores, mas que infelizmente carecia de ordem e instrumentos de busca e recuperação das informações nele contidas.

Por muito tempo a documentação do Apesp permaneceu organizada por período histórico. Essa periodização, adotada no século XIX e baseada no fatiamento da história em recortes temporais, foi muito comum nos arquivos e dividiu o acervo do Apesp em documentos produzidos no período colonial, no tempo do Império e durante a República. O principal problema dessa prática é que ela compromete a compreensão da organicidade natural dos documentos, bem como seu propósito e sentido. Além disso, esse tipo de arranjo desconsidera a história custodial dos arquivos, que nada têm a ver com o fatiamento cronológico proposto pelos livros de história. Até há bem pouco tempo, os documentos da Secretaria de Governo da capitania não figuravam nos instrumentos de pesquisa do Apesp como um conjunto de documentos organicamente produzido por uma entidade no exercício de suas atribuições. Agrupados com documentos de origem e natureza diversa, como testamentos 
e registros notariais, os maços e livros acumulados pelos capitães-generais eram tratados como peças avulsas de uma vasta coleção de documentos reunidos sob o rótulo de Tempo Colonial.

Em 2013 iniciou-se um trabalho de identificação dos fundos documentais do Apesp com o objetivo de adequar o seu guia de acervo às normas de descrição arquivísticas de âmbito internacional - ISAD $(\mathrm{G})$, ISAAR (CPF), ISDIAH e ISDF -, definindo a proveniência e o potencial informativo dos seus documentos. Um estudo da constituição do acervo do Apesp indicava que os sedimentos mais profundos do seu arquivo tinham origem na formação da capitania de São Paulo. Logo os técnicos do Núcleo de Acervo Textual Público perceberam que estavam diante de um fundo acumulado pelos secretários de governo que serviram aos capitães-generais da capitania desde os seus primórdios. Não se pode afirmar que esses documentos eram desconhecidos, porque vários deles aparecem transcritos e publicados nos volumes da coleção Documentos Interessantes. Porém, a ideia de organicidade desses documentos - isto é, do vínculo de cada documento com o seu produtor, com o contexto em que foi produzido e com os demais documentos que o cercam - tinha se perdido, desconhecendo-se sua integralidade e dimensão. Portanto eles não se conversavam, nem se completavam.

No meio arquivístico é usual a analogia dos arquivos com organismos vivos, que crescem naturalmente, se desenvolvem e sofrem transformações de acordo com as modificações operadas nos seus órgãos produtores. Do mesmo modo, comparam-se os depósitos de arquivos com formações geológicas, por lembrarem sedimentos de rocha depositados pela ação do tempo um sobre os outros (Bautier, 1961). O professor Bruno Delmas (2010, p.85), da École Nationale des Chartes, costuma relacionar o trabalho do arquivista com o do glaciologista, o cientista que estuda a formação das geleiras. O especialista em geleiras observa minuciosamente o acúmulo das camadas de gelo, sua composição, empilhamento e dinâmica de escoamento para o mar. O arquivista faz o mesmo com os fundos de arquivo, reconstituindo o contexto de acumulação de documentos produzidos durante dezenas de anos, tornando-os acessíveis e inteligíveis ao pesquisador. Nesse trabalho, o arquivista se defronta com as diversas intervenções impostas aos documentos, as quais, somadas às vicissitudes do tempo, resultam quase sempre em um desafio para aqueles que pretendem recuperar a história e a lógica desses acervos.

De maneira geral, a organização de um fundo deve representar a lógica de funcionamento da sua entidade produtora, contribuindo para o entendimento 
das funções e atividades geradoras dos documentos. No caso do Apesp, uma parte expressiva do acervo sob sua guarda foi organizada e modificada ao longo dos anos seguindo procedimentos diversos e intervenções descontinuadas que privilegiaram a ordenação por período histórico, misturando documentos de diferentes proveniências. Conhecer a proveniência de um documento significa saber por quem ele foi produzido, com que fim, para quem, como ele foi acumulado e veio parar em nossas mãos. Nos arquivos permanentes, a informação fornecida pela proveniência permite agrupar, contextualizar e ordenar os documentos, facilitando a localização e estabelecendo parâmetros seguros para sua interpretação, além de melhorar significativamente os instrumentos de pesquisa oferecidos ao pesquisador e ao público em geral. Consequentemente, identificar a proveniência dos documentos constitui o ponto de partida para se descrever os documentos de um arquivo.

Uma das principais atividades de um arquivo é a descrição dos seus conjuntos documentais (Heredia Herrera, 2013). O trabalho de descrição requer uma pesquisa histórica sólida, embasada em documentos como leis, decretos e regulamentos. Descrever, define a norma do Conselho Internacional de Arquivos, é explicar o contexto e o conteúdo dos documentos para promover o seu acesso (Conselho..., 2001, p.1). É por meio desse trabalho meticuloso que o arquivista contribui com o oficio do historiador, a quem compete pesquisar, relacionar fatos e interpretar o conteúdo dos documentos, construindo narrativas consistentes. Ainda que a pesquisa sobre arquivos não tenha, até o momento, despertado nos historiadores a devida atenção, dentro dos arquivos não há escapatória. Conhecer a totalidade do acervo sob sua guarda é fundamental para promover a preservação do seu patrimônio documental, pois somente aquilo que se conhece e valoriza é protegido e preservado.

Num esforço para conhecer profundamente o acervo e o patrimônio documental do Estado, os técnicos do Apesp mergulharam na documentação, trazendo à superfície o arquivo da capitania de São Paulo. Despois de um mapeamento de todo o acervo legado desde 1892, constatou-se que os documentos da Secretaria de Governo da capitania estavam distribuídos por 135 latas de documentos e 298 livros de registro, parte deles abrigados dentro de latas. Descobriu-se também que as pistas sobre a formação desse fundo estavam nos seus próprios documentos. A correspondência do capitão-general Rodrigo César de Meneses, por exemplo, revelava que uma das primeiras providências do governador da capitania, ao se estabelecer em São Paulo em 1721, foi pedir cópias dos regimentos, provisões, leis e alvarás de Sua Majestade, para 
formar um arquivo que amparasse sua tomada de decisões. O traslado desses documentos, arrecadados nos arquivos do Rio de Janeiro, permitiu a confecção do primeiro livro de registro de ordens e provisões da Secretaria de Governo da capitania. ${ }^{4} \mathrm{O}$ exame desse livro indica que muitos documentos trasladados eram cópias de cópias de regimentos e ordens régias que circulavam pelo Brasil desde 1611.

Os capitães-generais atuavam como governadores e comandantes militares das capitanias, com relativa independência perante o vice-rei. Essa condição parece ter sido encorajada pela Coroa e fica evidente no volume de correspondência entre a capitania de São Paulo e Lisboa, se comparado a dos documentos trocados entre o capitão-general e o vice-rei. De fato, o capitão-general era homem de confiança do rei, integrado ao sistema de poder por laços de sangue, títulos e mercês. As qualidades que norteavam a escolha dos capitães-generais eram, invariavelmente, o sangue nobre, a idade madura, a experiência militar e os laços de amizade na Corte (Souza, 2006, p.45; Silva, 2013, p.66).

O primeiro capitão-general a governar a capitania de São Paulo foi o fidalgo Rodrigo César de Meneses, que teve como secretário Gervásio Leite Rebelo, militar letrado que havia servido com distinção na capitania do Maranhão. Todos os capitães-generais tinham junto a si um secretário, encarregado de organizar os papéis que vinham do Reino bem como os que para lá seguiam, fazendo a expedição, tramitação e registro de toda a documentação produzida ou recebida pelo governo da capitania. O secretário tinha ainda a incumbência de fornecer certidões, dar publicidade aos atos oficiais e manter em boa ordem o arquivo. O secretário de governo era, na feliz expressão de Margarita Gómez Gómez (2005), um profissional da pluma, isto é, um exímio artífice de documentos e conhecedor da sua linguagem. A importância do cargo fica evidente na provisão do primeiro secretário do Brasil, Bernardo Vieira Ravasco, irmão do padre Vieira, nomeado em 1646 para servir ao governador geral na Bahia (Puntoni, 2005). Num breve trecho da provisão, guardada no Arquivo Ultramarino, a Coroa reclama para o Brasil arquivos bem organizados e funcionários que os mantenham em ordem:

para bem governar [o Brasil] será conveniente haver nele um secretário, assim como há na Índia, que tenha a seu cargo os papéis daquele governo com que se dará melhor expediente dos negócios a serem encaminhados, cessando os inconvenientes que se tem experimentado por não haver pessoa permanente nes- 
se ofício, nem arquivo em que se guarde os ditos papéis, ficando por esta causa os governadores que entram naquele Estado faltos de notícias dos negócios começados. ${ }^{5}$

A provisão do secretário Bernardo Vieira Ravasco deu início à organização dos arquivos no Brasil, estabelecendo as responsabilidades arquivísticas dos secretários de governo. Os secretários da capitania de São Paulo eram costumeiramente militares de baixa patente com boa letra e "sangue limpo", ou seja, com comprovada ascendência católica, sem sangue judeu ou mouro (Silva, 2013). O desembargador José Teixeira Coelho (1994, p.101), oficial do rei na capitania mineira, escreveu que o emprego de secretário era "uma grande consideração" exercida por "pessoas de talentos conhecidos, instruídas e honradas por seu nascimento". Os regimentos passados aos secretários trazem instruções que nos ajudam a compreender a lógica organizacional do arquivo da Secretaria. A respeitos dos livros, o regimento determina: “Terá livros de registro separados, uns para as ordens que forem de Portugal, e outros para as que se passarem na dita capitania ... e nenhuma ordem sairá da Secretaria sem que fique registrada" (Boschi, 2011, p.98-100).

Na Secretaria existiam livros copiadores, livros de registro e livros de assentamento, além dos cartulários, que nada mais eram do que encadernações de cartas, avisos, decretos e outros documentos recebidos de Lisboa. A escrituração e guarda desses livros ficava a cargo do secretário de governo, a quem cabia o registro de todos os atos da administração. Como autoridade soberana e representante da vontade real no território da capitania, os capitães-generais valiam-se do privilégio de conceder provisões, nomear serventuários e ditar normas no âmbito de suas competências, controlando a distribuição de terras e mercês, e tornando os documentos imprescindíveis para certificar cartas de doação, concessões de mercês e decisões régias. Os documentos do fundo confirmam que a administração da capitania estava assentada num complexo sistema de doações de terras, mercês e privilégios, que precisavam ser registrados em livros "para que não se perca a memória de todas as mercês que fizer" ${ }^{6}$

O poder de conceder sesmarias para povoar e cultivar a terra era atribuição exclusiva do rei que se estendeu aos capitães-generais, provedores e oficiais das câmaras municipais, com o intuito de melhor efetivar a distribuição de terras (Porto, s.d.; Gleizer, 2008). Em troca, o beneficiário ficava obrigado a tornar a terra produtiva e cumprir as determinações régias. No caso das terras concedidas pelos capitães-generais, o documento específico dessa doação era 
a carta de sesmaria que, após ser registrada nos livros da Secretaria de Governo da capitania, deveria ser enviada a Lisboa para ser confirmada pelo rei no prazo de 2 anos. O capitão-general ficava responsável por fiscalizar o uso que se fazia da terra e arbitrar as disputas. Esse sistema de doações de mercês permitiu à Coroa distribuir cargos e conceder privilégios a grupos ou pessoas e, por meio dessas doações, dispor de rendimentos com base nos quais se distribuíam as pensões dos servidores reais (Gouvêia, 2001).

Além dos livros, a administração da capitania acumulou vasta correspondência organizada em maços. Tais maços eram compostos por diversos tipos de documentos, produzidos por autoridades da metrópole e da colônia, bem como por particulares solicitando mercês e terras ou recorrendo de alguma sentença. Rodrigues e Silva (2012) explicam que os maços não eram apenas uma forma de acondicionamento da documentação, mas uma unidade constituída com critérios predeterminados. A constituição dos maços prendia-se à necessidade de recuperar parte da informação e não o todo, como ocorria com os livros. Os critérios para o arranjo dos documentos em maços variavam, mas geralmente estavam relacionados com atos administrativos, tipos documentais e o remetente dos documentos (Martins, 2007, p.202-231). No arquivo da Secretaria de Governo da capitania de São Paulo predominou o arranjo por atos e tipos documentais (ordens régias, petições e listas de companhias de praças) e remetente (cartas dos moradores da capitania, das câmaras das vilas, de Lisboa e da Secretaria do Rio de Janeiro).

Tanto o conteúdo dos maços quanto o dos livros eram localizados para consulta por meio de inventários cuidadosamente elaborados pelos secretários de governo. A finalidade dos inventários do século XVIII era tripla: primeiro, servir à busca e recuperação dos documentos; segundo, registrar a existência dos documentos no arquivo; e, terceiro, garantir a ordem e a preservação dos papéis acumulados pelos secretários para os seus sucessores. O primeiro inventário dos documentos da Secretaria de Governo foi preparado pelo secretário Gervásio Leite Rebelo, que registrou 20 livros e 12 maços de documentos. No termo de abertura do inventário Rebelo deixa claro o propósito daquele instrumento:

Este livro há de servir de inventário assim dos livros em que principiou esta Secretaria de Governo de São Paulo no seu estabelecimento que teve princípio em 5 de setembro de 1721, como dos papéis que neles se registrarão que são regimentos, leis, alvarás, provisões, cartas, e vários papéis que trouxe da Secretaria, 
Ouvidoria Geral, e Fazenda Real do Rio de Janeiro, Gervásio Leite Rebelo, primeiro secretário deste governo; e de outros que vieram da Secretaria deste estado, como também das ordens, e cartas que vieram de Sua Majestade que Deus guarde para este governo, e de todos os mais papéis que se acham nesta Secretaria em maços com seus títulos e números, que tudo lancei neste livro para melhor arrecadação, aonde os secretários que vierem a este governo vão lançando os do seu tempo, para que em todo se possa saber com facilidade as ordens que nele há, ainda que poderá suceder vir algum tão perito que quererá emendar esta ordem, por ser trivial desfazerem os modernos o que fizeram seus antecessores, e porque esta forma julguei necessária, elegi fazer na forma seguinte este inventário, separando os livros de cartas e estes dos maços de papéis avulsos, com títulos separados para que pelo tempo adiante se possam ir carregando cada um na parte a que pertencer, por ser assim conveniente ao Real Serviço, e o se poder saber com facilidade, não só as ordens que há nesta Secretaria, mas o ano em que vieram e o que contêm. ${ }^{?}$

Os inventários elaborados pelos secretários de governo (o primeiro iniciado em 1721 e o último, em 1807) foram indispensáveis para a reconstituição do fundo, permitindo entender a maneira como se arrolavam seus documentos, além de atestar a integralidade do fundo. No final do primeiro inventário ficamos sabendo que Gervásio Leite Rebelo, ao deixar a Secretaria em 1732, entregou o arquivo para o capitão-general Antônio da Silva Caldeira Pimentel, por não haver secretário a quem ele formalizasse a entrega. Todas as transmissões de secretários ficavam registradas nos inventários, e, extinta a capitania em 1749, os seus papéis e livros foram conferidos e guardados em arcas, depositadas no Colégio de São Miguel, na vila de Santos. Durante esse período, o governador da Praça de Santos prosseguiu administrando parte da capitania e produzindo documentos que vieram a ser incorporados ao arquivo da Secretaria. Em 1765 a capitania de São Paulo foi restabelecida, e seu arquivo, restaurado. No ano seguinte o capitão-general Luís Antônio de Souza Botelho Mourão instalou-se em São Paulo, ocupando o colégio jesuíta transformado em sede do governo. Instituiu-se ali o arquivo da Secretaria que, com o passar dos anos, cresceu e acumulou uma variedade de documentos que davam suporte ao governo da capitania, e mais tarde ao da província.

O surgimento de novos tipos documentais e a modificação de outros evidenciam as transformações ocorridas na administração da capitania e do Reino, durante o período anterior à independência do Brasil. Em 1765, por exemplo, o rei mandou proceder ao levantamento de todos os habitantes de 
seus domínios, e assim surgiram os mapas de população, confeccionados pelos ordenanças e resumidos pelos secretários de governo num mapa geral, que descrevia o número de fogos (moradias), nome dos habitantes, idade, cor, estado civil, profissão e cabedais (Marcílio, 2000, p.33-38). Observa-se que durante o século XVIII os ofícios foram gradualmente ocupando o lugar das cartas, disciplinando o seu uso e as regras de produção dos documentos oficiais. Os livros de registros se multiplicaram e os de porta, como eram chamados os livros para registro de entrada de documentos e despachos da Secretaria, se consolidaram. Desses livros se originaram os procedimentos de protocolo atuais. Em 1792, um aviso do capitão-general determinava que não seriam mais aceitas expressões impróprias nos requerimentos. Exige-se cortesia na linguagem oficial. Em 1808, com a abertura dos portos, todos os capitães-generais receberam ordens para controlar a circulação de naus, abarrotando os arquivos de passaportes e livros de controle de entrada e saída de pessoas da capitania (Mattos, 2015). Em face das mudanças o trabalho na Secretaria aumenta e, em 1821, o secretário Manuel Chichorro reclama aos seus superiores não haver pessoal suficiente para pôr em dia a escrituração de todas as ordens recebidas e expedidas, bem como dos ofícios dirigidos à Corte, e mesmo trabalhando durante a noite não seria possível cumprir o expediente. ${ }^{8}$

O governo dos capitães-generais prolongou-se até 1821, quando as Cortes de Portugal instalaram as Juntas Provisórias de governo, numa tentativa de assenhorar-se das províncias brasileiras (Cabral, 2015, p.20-23). Em 1823, com a consumação da separação de Portugal, Pedro I suprimiu as Juntas e criou o cargo de presidente de província na estrutura de governo do Império brasileiro. ${ }^{9}$ A Secretaria de Governo da província de São Paulo permaneceu instalada no prédio ocupado pelos capitães-generais, herdando o arquivo acumulado pelos governadores da capitania e pela Junta Provisória de governo. No momento em que esses documentos perderam valor legal, o arquivo dos capitães-generais tornou-se inativo, mas de modo algum esquecido, como revelam os relatórios dos presidentes de província.

Em 1842, o barão de Mont'Alegre, no exercício do cargo de presidente da província, aprovou uma lei criando um arquivo público em São Paulo. A lei, inspirada nas instituições europeias, determinava a transferência e guarda dos documentos das secretarias e provedorias anteriores à separação de Portugal, dando abrigo a "tudo que possa interessar à história da província" ${ }^{10}$ Porém a iniciativa não frutificou. Alegando falta de recursos e outras prioridades, o sucessor do barão não colocou a lei em prática, mas reconheceu a existência 
dentro da Secretaria de um conjunto de documentos "preciosos para a história”, que lamentavelmente continuariam "entregues ao pó e as traças" (Discurso..., 1852, p.38).

Os relatórios dos presidentes de província afirmam que os documentos da capitania foram mantidos no interior do arquivo da Secretaria de Governo da província até sua extinção, em 1892. No intuito de proteger esses documentos, o regulamento do arquivo expedido em 1855 recomendava que os documentos produzidos pelos capitães-generais ficassem guardados em um armário próprio, separados dos demais papéis. ${ }^{11}$ Considerados um fundo de valor histórico, os documentos anteriores à Independência atraíram a curiosidade de membros do Instituto Histórico e Geográfico Brasileiro, entre eles o brigadeiro José Joaquim Machado de Oliveira (1978), que escreveu um quadro histórico da província para uso nas escolas, publicado em 1864. Em 1881, o presidente Laurindo Abelardo de Brito solicitou à Assembleia Provincial verba para a remoção e organização do acervo acumulado no tempo da capitania. ${ }^{12} \mathrm{O}$ trabalho de classificação, levado a cabo entre 1882 e 1885, produziu um índice de papéis chamado Catálogo $n^{\circ} 1$ - Tempo Colonial. Esse catálogo relacionava 144 maços e 298 livros de registro acumulados no período anterior à Independência, conservando a ordem dos documentos. ${ }^{13}$ Em 1888 o secretário de governo Estevão Leão Bourroul fez reparos ao catálogo e criticou a liberdade com que o arquivo foi franqueado "aos colhedores de documentos e esclarecimentos históricos", a quem ele culpava pelos desfalques na documentação (Sucinta..., 1888, p.10).

Após a proclamação da República, em 1892, o arquivo da Secretaria de Governo passou para a custódia do Apesp, criado anexo à Secretaria do Interior com a denominação de Repartição de Estatística e Arquivo do Estado, para reunir e preservar uma parte da documentação de valor histórico sob guarda do governo paulista. ${ }^{14}$ Junto ao acervo da extinta Secretaria foram incorporados fundos de outras proveniências, especialmente dos cartórios e juízos da capital, anteriores ao século XIX. ${ }^{15} \mathrm{Um}$ dos mais operosos diretores da Repartição, Antônio de Toledo Piza, mandou transcrever centenas de documentos extraídos do arquivo da Secretaria de Governo da capitania, que ele fez publicar numa coleção chamada de Documentos Interessantes para a História e os Costumes de São Paulo. Toledo Piza era um engenheiro de estradas de ferro que demonstrava vivo interesse pelo passado paulista. Embora tenha examinado quase todos os papéis da capitania, selecionando peças para 
transcrição e publicação, Toledo Piza não chegou a preparar um catálogo desses documentos, falecendo inesperadamente em 1905.

Durante a primeira metade do século XX, a documentação do Apesp permaneceu organizada em maços, envoltos por capilhas produzidas nos seus órgãos de origem com indicação do assunto e ano a que pertenciam. Para melhor servir aos historiadores os maços e livros foram classificados de acordo com seu período histórico, sem maiores preocupações de âmbito arquivístico. Após a Revolução de 1930, o Arquivo Público do Estado esgotou sua capacidade de abrigar documentos e começou a definhar, deixando de recolher acervos novos e publicar transcrições. Em 1945, a prefeitura de São Paulo pediu a desocupação do prédio onde estava instalado o Apesp para alargar as avenidas centrais da cidade. De certa forma, não surpreende que um projeto com olhos fixos para o futuro desprezasse prédios antigos, ruas estreitas e um Arquivo que, em função de não ser uma repartição arrecadadora, para alguns não passava de um "peso morto" no organograma da administração. ${ }^{16}$ No final de 1949, o Arquivo Público do Estado foi desalojado da noite para o dia. Caminhões e funcionários da prefeitura descarregaram quase 10 milhões de documentos em um armazém da Estrada de Ferro Sorocabana. Os funcionários do Arquivo acompanharam o transporte, evitando perdas e estragos na documentação. Na falta de prateleiras foram traçadas linhas no chão com giz, para separar os conjuntos documentais e manter sua ordem.

Em 1954 o Apesp foi transferido para o prédio de uma fábrica de tapetes, reformada para abrigar seu acervo histórico. Os documentos foram então acondicionados em latas de alumínio, fabricadas para proteger os papéis da umidade, do risco de incêndio e do perigo de infestação por pragas. Na prática, as informações das capilhas dos maços foram transferidas para as etiquetas das latas. As etiquetas traziam as letras TC (Tempo Colonial), TI (Tempo do Império) e TR (Tempo da República), mantendo a organização do acervo atrelada à periodização histórica. $\mathrm{O}$ controle das latas era feito por fichas datilografadas contendo indicações sumárias do assunto e data dos documentos. Com o passar dos anos cada lata passou a ser tratada na sua individualidade, como se fosse um livro de determinado assunto, perdendo-se a dimensão dos fundos que compunham o acervo.

Em 1970, diante do crescimento contínuo do acervo, a seção histórica do Arquivo elaborou um catálogo topográfico para melhor controlar e localizar os documentos. Esse trabalho foi realizado por duas antigas servidoras, que copiaram o número de ordem e o rótulo de cada lata. Em 1975 os jornais 
denunciaram que o Apesp encontrava-se em situação de quase abandono. ${ }^{17}$ Nessa ocasião, o secretário da cultura José Mindlin convidou o escritor e editor do Instituto Nacional do Livro, Francisco de Assis Barbosa, para assumir o cargo de consultor técnico do Apesp, com a missão de apresentar sugestões urgentes que garantissem a segurança do acervo e a renovação da instituição. Barbosa criticou os últimos secretários, que na sua visão não tiveram capacidade para compreender a importância do Arquivo e permitiram que traças consumissem 30\% do acervo. Em relatório, o consultor técnico do Apesp defendeu a necessidade de se publicar um catálogo dos manuscritos da capitania, seguindo os procedimentos de organização de fundos implantado no Arquivo Nacional pelo arquivista francês Henri Boullier de Branche. ${ }^{18}$

Estimulada pelas iniciativas de modernização dos arquivos que tomaram impulso no Brasil nos anos 1980, a professora da Universidade de São Paulo (USP) Ana Maria de Almeida Camargo iniciou a preparação de um estudo histórico da administração pública paulista, com ajuda de jovens arquivistas, compilando organogramas e repertórios de leis para subsidiar a montagem de um quadro de fundos, mas o trabalho não teve continuidade. Em 1990 o catálogo topográfico foi transformado em um guia de acervo improvisado. A iniciativa pretendia ser um primeiro passo para a identificação parcial dos fundos que compunham o acervo da instituição. O volume 1 do guia listou 1.629 latas, agrupando todos os conjuntos documentais produzidos no período anterior à Independência (Guia..., 1999, p.3). Sete anos depois, o Apesp publicou um guia que apresentava de maneira ampla e panorâmica todo o seu acervo de origem pública, ainda que parcialmente identificado. Nele, os documentos da Secretaria de Governo da capitania apareciam dispersos em conjuntos designados "correspondência dos capitães-generais", "avisos régios" e "registros de terras".

A primeira tentativa de organizar um quadro de fundos do Apesp veio a se concretizar apenas em 2010, por meio de um guia que sofria de várias deficiências. A principal delas era não informar a natureza e a origem dos documentos, carecendo de informações consistentes sobre a história e o contexto de produção da maioria dos seus fundos. Com base nesse diagnóstico, um grupo de técnicos do Apesp propôs a revisão criteriosa do guia, no sentido de adequá-lo aos padrões internacionais de descrição arquivística, recuperando a organicidade do acervo e oferecendo ao pesquisador um instrumento de pesquisa mais completo e eficiente. Em 2013, o Núcleo de Acervo Textual Público iniciou o tratamento arquivístico dos documentos conhecidos nos instrumentos 
topográficos como Tempo Colonial, dando continuidade ao trabalho iniciado pela professora Ana Maria de Almeida Camargo no final da década de 1980. Esse trabalho resultou na descrição do arquivo da Secretaria de Governo da capitania de São Paulo e num inventário apoiado na compreensão das funções e atividades geradoras dos seus documentos (Inventário..., 2016).

\section{CONSIDERAÇÕES FINAIS}

O caso do arquivo da Secretaria de Governo da capitania de São Paulo, aqui relatado, permite compreender como a história dos arquivos pode ser resgatada do interior dos arquivos, reconstruindo o contexto de produção e acumulação dos seus documentos. Devemos reconhecer que, historicamente, os arquivos sempre estiveram sujeitos a várias ameaças, desde o risco de perda da sua integridade, mediante dispersão e desmembramento dos fundos, até a simples destruição dos documentos, motivada por calamidades, mau acondicionamento e negligência. Atualmente, essas ameaças são acrescidas da obsolescência tecnológica e vulnerabilidade intrínseca dos arquivos digitais. Alguns arquivos das capitanias sobreviveram a todos esses riscos e merecem ser descritos, restaurados e divulgados, devolvendo sua condição de dialogar com outros acervos, especialmente com os das demais capitanias e com os documentos guardados no Arquivo Histórico Ultramarino, em Portugal. Esse é um desafio que poderia congregar historiadores e arquivistas incentivando uma interação promissora entre esses dois campos profissionais. Mas talvez o mais importante, tanto para o historiador como para o arquivista, seja a constatação de que todo arquivo é historicamente produzido e que a sua transformação em fonte histórica é um processo que não pode continuar à mercê da sorte.

\section{REFERÊNCIAS}

BAUTIER, Robert-Henri. Les Archives. In: SAMARAN, Charles (Dir.) L'Histoire et ses méthodes. Paris: Gallimard, 1961.

BELLOTTO, Heloísa L. Diplomática luso-brasileira do século XVIII: tipologia dos documentos ascendentes e descendentes. In: Arquivos: estudos e reflexões. Belo Horizonte: Ed. UFMG, 2014.

BOSCHI, Caio C. Os secretários do governo da Capitania de Minas Gerais. In:

Exercícios de pesquisa histórica. Belo Horizonte: Ed. PUC Minas, 2011. 
BOSCHI, Caio C.; MORENO, Carmen; FIGUEIREDO, Luciano (Coord.) Inventário da Coleção Casa dos Contos: livros, 1700-1891. Belo Horizonte: Ed. PUC Minas; Fapemig, 2006.

CABRAL, Dilma (Org.) Estado e administração: a construção do Brasil independente (1822-1840). Rio de Janeiro: Arquivo Nacional, 2015.

COELHO, J. J. Teixeira. Instrução para o governador da Capitania de Minas Gerais (1780). Belo Horizonte: Fundação João Pinheiro, 1994.

CONSELHO INTERNACIONAL DE ARQUIVOS (CIA). ISAD(G): Norma geral internacional de descrição arquivística. 2.ed. (adotada pelo Comitê de Normas de Descrição, Estocolmo, Suécia, 19-22 set. 1999, versão final aprovada pelo CIA). Rio de Janeiro: Arquivo Nacional, 2001.

DELMAS, Bruno. Arquivos para quê? Textos escolhidos. São Paulo: Instituto Fernando Henrique Cardoso, 2010.

DISCURSO com que o Ilustríssimo e Excelentíssimo Senhor Dr. José Thomas Nabuco D’Araujo, presidente da Província de S. Paulo, abriu a Assembléia Legislativa Provincial no dia $1^{\circ}$ de maio de 1852. São Paulo: Typ. do Governo Arrendada, 1852, p.38.

FRAGOSO, João; GUEDES, Roberto; KRAUSE, Thiago. A América portuguesa e os sistemas atlânticos na Época Moderna. Rio de Janeiro: Ed. FGV, 2013.

GLEIZER, Raquel. Chão de Terra e outros ensaios sobre São Paulo. São Paulo: Alameda, 2008.

GÓMEZ GÓMEZ, Margarita. Actores del Documento: Oficiales, archiveros y escribientes de la Secretaria de Estado y del Despacho Universal de Indias durante el siglo XVIII. Madrid: Centro de Estudios Políticos y Constitucionales, 2003.

. Gobernar la palabra: los ofícios de la pluma como agentes de la administración pública de Índias. In: JORNADAS SOBRE ÉLITES URBANAS EN HISPANOAMÉRICA (coord. Luis Navarro García). Sevilla: Universidad de Sevilla, 2005, pp. 541-555.

GOUVÊIA, Maria de Fátima S. Poder político e administração na formação do complexo atlântico português (1645-1808). In: FRAGOSO, João; BICALHO, Maria Fernanda; GOUVÊIA, Maria de Fátima (Org.) O Antigo Regime nos Trópicos: a dinâmica imperial portuguesa (séculos XVI-XVIII). Rio de Janeiro: Civilização Brasileira, 2001. p.287-315.

GUIA do Acervo Permanente. v.I - Colônia (1578-1822). São Paulo: Arquivo Público do Estado, 1999.

HEREDIA HERRERA, Antonia. Manual de Archivistica Básica: gestión y sistemas. Puebla: Benemérita Universidad Autónoma de Puebla, 2013.

INVENTÁRIO de Documentos da Secretaria de Governo da Capitania de São Paulo (1721-1823). São Paulo: Apesp, 2016. (PDF). Disponível em: http://www.arquivoestado.sp.gov.br/site/acervo/textual/inventarios. 
LEGISLAÇÃO Brasileira ou Coleção Cronológica de Leis, Decretos, Resoluções de Consulta, Provisões etc. do Império do Brasil, desde o ano de 1808 até 1831 inclusive. Coligidas pelo Conselheiro José Paulo de Figueiroa Nabuco Araújo. Tomo IV. Rio de Janeiro: J. Villeneuve e Comp., 1838.

LEIS da Assembleia Legislativa Provincial de S. Paulo para o ano de 1842. São Paulo: Tipografia do Governo, 1842.

MARCÍLIO. Maria Luiza. Crescimento demográfico e evolução agrária paulista (17001836). São Paulo: Hucitec, 2000.

MARTINHEIRA, José J. Sintra. Tipologias documentais da administração central no Antigo Regime. Lisboa: s.n., 1997.

MARTINS, Ana Canas D. Governação e Arquivos: D. João VI no Brasil. Lisboa: Instituto dos Arquivos Nacionais/Torre do Tombo, 2007.

MARTINS, Marcelo Thadeu Q. Maços, latas e softwares: o Arquivo Público do Estado de São Paulo e suas reconfigurações. Acervo, Rio de Janeiro: Arquivo Nacional, v.26, n.2, p.231-242, jul./dez. 2013.

MATTOS, Renato de. Governança, fiscalidade e negócios: a emissão de passaportes marítimos e a regulamentação da navegação mercantil na capitania/província de São Paulo (1808-1821). In: ENCUENTRO DE GEOHISTORIA REGIONAL, 35. - SEMANA DE HISTÓRIA, 20. - CONGRESSO INTERNACIONAL DE HISTÓRIA DA UEM, 7., 6-9 out. 2015, Maringá, PR. Disponível em: http://www.cih.uem. br/anais/2015/trabalhos/1501.pdf.

MELO, Josemar Henrique de. Os acervos coloniais e os secretários de governo das capitanias: o início dos arquivos no Brasil. Ciência da Informação, Brasília, v.41, n.1, jan./abr. 2013.

MENDONÇA, Marcos Carneiro de. Raízes da formação administrativa do Brasil. Rio de Janeiro: IHGB; Conselho Federal de Cultura, 1972.

NEVES, Marta Eloísa M. Em busca da organicidade: um estudo do fundo da Secretaria de Governo da Capitania de Minas Gerais. Dissertação (Mestrado) - Escola de Biblioteconomia, Universidade Federal de Minas Gerais (UFMG). Belo Horizonte, 1997.

OLIVAL, Fernanda. Mercês, serviços e circuitos documentais no Império Português. In: SANTOS, Maria Emília M.; LOBATO, Manuel (Coord.) O domínio da distância: comunicação e cartografia. Lisboa: Instituto de Investigação Científica Tropical, 2006.

OLIVEIRA, J. J. Machado de. Quadro Histórico da Província de São Paulo. São Paulo: Governo do Estado, 1978.

PORTO, José da Costa. O sistema sesmarial no Brasil. Brasília: Ed. UnB, s.d.

PUBLICAÇÃO Oficial de Documentos Interessantes para a História e os Costumes de S. Paulo. v.XLVII. São Paulo: Casa Vanorden, 1929. 
PUNTONI, Pedro. Bernardo Vieira Ravasco, Secretário do Estado do Brasil: poder e elites na Bahia do século XVII. In: BICALHO, Maria Fernanda; FERLINI, Vera Lúcia A. (Org.) Modos de governar: ideias e práticas políticas no Império Português, séculos XVI a XIX. São Paulo: Alameda, 2005. p.157-178.

RAMINELLI, Ronald. Serviços e mercês de vassalos da América Portuguesa. Revista História y Sociedad, Medellín, n.12, p.107-131, nov. 2006. Disponível em: https:// cienciashumanasyeconomicas.medellin.unal.edu.co/revistas/historiaysociedad/ images/default/files/hys/pdf/hys_12/hys_12_04_raminelli_ronald_-_servicos_merces_vassalos.pdf.

REGULAMENTOS expedidos pelo Exmo. Governo Provincial para execução de diversas leis provinciais, coligidos e anotados pelo bacharel José Candido de Azevedo Marques e mandados imprimir pelo Exmo. Sr. Dr. João Teodoro Xavier, presidente da Província de S. Paulo. São Paulo: Tip. do Correio Paulistano, 1874.

RODRIGUES, Abel; SILVA, Armando M. da. A criação das Gavetas na Casa de Mateus: um modelo iluminista de gestão da informação. In: ROSA, Maria de Lurdes (Org.) Arquivos de Família, séculos XIII-XX: que presente, que futuro? Lisboa: IEM-CHAM, 2012. p.597-650.

RODRIGUES, Leda Maria P. As Minas de Ferro de Biraçoiaba (São Paulo, séculos XVI-XVII-XVIII). In: SIMPÓSIO DOS PROFESSORES UNIVERSITÁRIOS DE HISTÓRIA, 3., nov. 1965, Franca, SP. Anais... Franca: Anpuh, 1965.

SALDANHA, Antônio Vasconcelos de. As Capitanias: o regime senhorial na expansão ultramarina portuguesa. Funchal: CRTCE; Centro de Estudos de História do Atlântico, 1992.

SALGADO, Graça (Coord.) Fiscais e meirinhos: a administração no Brasil Colônia. Rio de Janeiro: Nova Fronteira, 1985.

SILVA, Thiago Rodrigues da. Secretários de Governo no centro sul da América portuguesa, 1688-1750: burocracia, segredo e missões. Dissertação (Mestrado em História Moderna) - Universidade Federal Fluminense (UFF). Niterói, 2013.

SOUZA, Laura de Mello e. O sol e a sombra: política e administração na América portuguesa do século XVIII. São Paulo: Companhia das Letras, 2006.

SUCINTA Exposição apresentada ao Exm. Snr. Dr. Francisco de Paula Rodrigues Alves, presidente da Província, pelo secretário bacharel Estevão Leão Bourroul. São Paulo: Tipografia a vapor de Jorge Seckler \& Comp., 1888.

TAUNAY, Afonso d'E. Encerramento do Curso de Paleografia. In: Curso livre de paleografia, organizado pelo Departamento do Arquivo do Estado. São Paulo: Departamento do Arquivo do Estado, 1952. 
Resgatando arquivos: história custodial do fundo Secretaria de Governo da Capitania de São Paulo

\section{NOTAS}

${ }^{1}$ Carta régia de 23 de novembro de 1709. In: PUBLICAÇÃO..., 1929, p.65-68.

${ }^{2}$ Alvará de 2 de dezembro de 1720. In: PUBLICAÇÃO..., 1929, p.87-90.

${ }^{3}$ Ver: http://www.arquivoestado.sp.gov.br/site/institucional/arquivo_numeros; acesso em: 2 mar. 2018.

${ }^{4}$ Livro de registro de regimentos, cartas, ordens e provisões de Sua Majestade (1611-1761). Livro 167 [1.4.135]. Apesp.

${ }^{5}$ Livro de Registro de Ofícios do Conselho Ultramarino (1644-1649), AHU_CU_OFÍCIOS, Cod. 113, fl. 186. Arquivo Histórico Ultramarino, Lisboa.

${ }^{6}$ Alvará de 28 de agosto de 1714. Coleção de alvarás, avisos e cartas régias da Secretaria de Governo da Capitania de São Paulo [1.1.802]. Apesp.

${ }^{7}$ Inventário dos livros e papéis da Secretaria de Governo de São Paulo (1721-1749). Livro 259 [1.1.771]. Apesp.

${ }^{8}$ Ofício do secretário de governo Manuel da Cunha Azevedo Coutinho de Souza Chichorro, de 18 de setembro de 1821 [1.1.148], maço 26, pasta 2, doc. 4. Apesp.

${ }^{9}$ Carta de Lei de 20 de outubro de 1823. In: LEGISLAÇÃO..., 1838, p.148-150.

${ }^{10}$ Lei no 196 de 8 de março de 1842, art.6, § 3. In: LEIS..., 1842.

${ }^{11}$ Regulamento de 4 de maio de 1855. In: REGULAMENTOS..., 1874, p.292.

${ }^{12}$ Lei provincial $\mathrm{n}^{\circ} 12$, de 13 de fevereiro de 1881. Disponível em: https://www.al.sp.gov.br/ repositorio/legislacao/lei/1881/lei-12-13.02.1881.html; acesso em: 15 maio 2018.

${ }^{13}$ Índice de papéis e livros existentes no arquivo da Secretaria de Governo relativo ao Tempo Colonial (1885). Documento sem notação. Apesp.

${ }^{14}$ Decreto $\mathrm{n}^{\circ}$ 30, de 10 de março de 1892. Disponível em: https://www.al.sp.gov.br/repositorio/legislacao/decreto/1892/decreto-30-10.03.1892.html; acesso em: 15 maio 2018.

${ }^{15}$ Lei no 666, de 6 de setembro de 1899. Disponível em: https://www.al.sp.gov.br/repositorio/legislacao/lei/1899/lei-666-06.09.1899.html; acesso em: 15 maio 2018.

${ }^{16}$ Correio Paulistano, São Paulo, 21 jul. 1940.

17 “A Destruição do Arquivo Público”. O Estado de S. Paulo, São Paulo, 11 jun. 1975.

${ }^{18}$ Arquivo do Governo do Estado de São Paulo. Problemas \& Soluções. Relatório apresentado ao Excelentíssimo senhor Max Feffer, Secretário de Estado da Cultura, Ciência e Tecnologia, pelo consultor técnico da Divisão de Arquivo do Estado, Francisco de Assis Barbosa, no período de janeiro de 1976 a 21 de janeiro de 1977, p.6-33.

Artigo recebido em 13 de fevereiro de 2018.

Aprovado em 11 de maio de 2018.

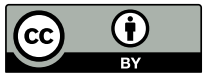

